\title{
Septate uterus: nosographic overview and endoscopic treatment
}

\author{
Antonio Perino • Francesco Forlani • Antonio Lo Casto • \\ Giuseppe Calì • Gloria Calagna • Stefano Rotolo • \\ Gaspare Cucinella
}

Received: 9 October 2013 / Accepted: 10 February 2014 / Published online: 26 February 2014

(C) Springer-Verlag Berlin Heidelberg 2014

\begin{abstract}
To comment on the prevalence, diagnosis, and treatment of the septate uterus, with special reference to hysteroscopic metroplasty and its effect on reproductive outcome, we searched publications in PubMed and Embase. Original articles, meta-analysis, reviews, and opinion articles were selected. The studies suggest that the prevalence of the septate uterus is increased in women with repeated pregnancy loss and infertility. Reliable diagnosis depends on accurate assessment of the uterine fundal contour and uterine cavity by means of magnetic resonance and three-dimensional ultrasound. Pertinent published data comparing pregnancy outcome before and after hysteroscopic metroplasty indicated a marked improvement after surgery. Magnetic resonance and threedimensional ultrasound represent the gold standard for diagnosis of septate uterus. Hysteroscopic metroplasty with its simplicity, minimal postoperative sequelae, and improved reproductive outcome is the gold standard for treatment, not only in patients with recurrent pregnancy loss and premature labor but also in patients with infertility, especially if in vitro fertilization is being contemplated.
\end{abstract}

Keywords Septate uterus · Miscarriage $\cdot$ Infertility · Hysteroscopy $\cdot$ Metroplasty

A. Perino $\cdot$ F. Forlani $(\bowtie) \cdot$ G. Calagna $\cdot$ S. Rotolo $\cdot$ G. Cucinella Department of Obstetrics and Gynecology, University Hospital "P. Giaccone", Palermo, Italy

e-mail: forlani81@gmail.com

\section{A. Lo Casto}

Department of Radiological Sciences, DIBIMEF, University

Hospital "P. Giaccone", Palermo, Italy

G. Calì

Department of Obstetrics and Gynecology, ARNAS Civico, Di Cristina e Benfratelli, Palermo, Italy

\section{Introduction}

Septate uterus results from the incomplete or completely failed fusion of Müllerian ducts and is the most common type among congenital uterine anomalies [1,2]. Two types of septate uterus are described: the complete septate uterus, in which the septum divides the whole uterine cavity, and the subseptate uterus, in which a partial separation of uterine cavity does not reach the cervix (Fig. 1a, b). Failure of fusion may even occur at a lower level, so that two cervices and even a vaginal septum may be present [3-6] (Fig. 1, d). The European Society of Human Reproduction and Embryology (ESHRE) and the European Society for Gynecological Endoscopy (ESGE) developed a new updated classification system of congenital uterine anomalies [7]. The uterus septum (category U2) was defined as the uterus with normal outline and an internal indentation at the fundal midline exceeding $50 \%$ of the uterine wall thickness. This indentation is characterized as septum and could divide partly or completely the uterine cavity, including in some cases cervix and/or vagina (cervical and vaginal coexistent anomalies). The true prevalence of Müllerian anomalies in the general population remains unknown. Mainly based on clinical exam, early investigations on congenital uterine anomalies were limited by the lack of diagnostic tools. A meta-analysis of 94 observational studies comprising nearly 90,000 women indicated a prevalence of $5.5 \%$ in the unselected population, $8.0 \%$ in infertile women, $13.3 \%$ in those with a history of miscarriage, and $24.5 \%$ in those with miscarriage and infertility [8]. Furthermore, canalization defects (subseptate or septate uteri) had a prevalence of $2.3 \%$ in the unselected population but were encountered significantly more frequently in women with previous miscarriage (5.3\%) [8]. In addiiton, septate uterus is associated with higher first and second trimester abortion rates, preterm labor, abnormal labor, intrauterine growth restriction, and infertility. These conditions may be attributed to 
Fig. 1 Sepatate uterus: partial (a) and complete (b). Uterine septum involving the cervix (c) and vagina $(\mathbf{d})$
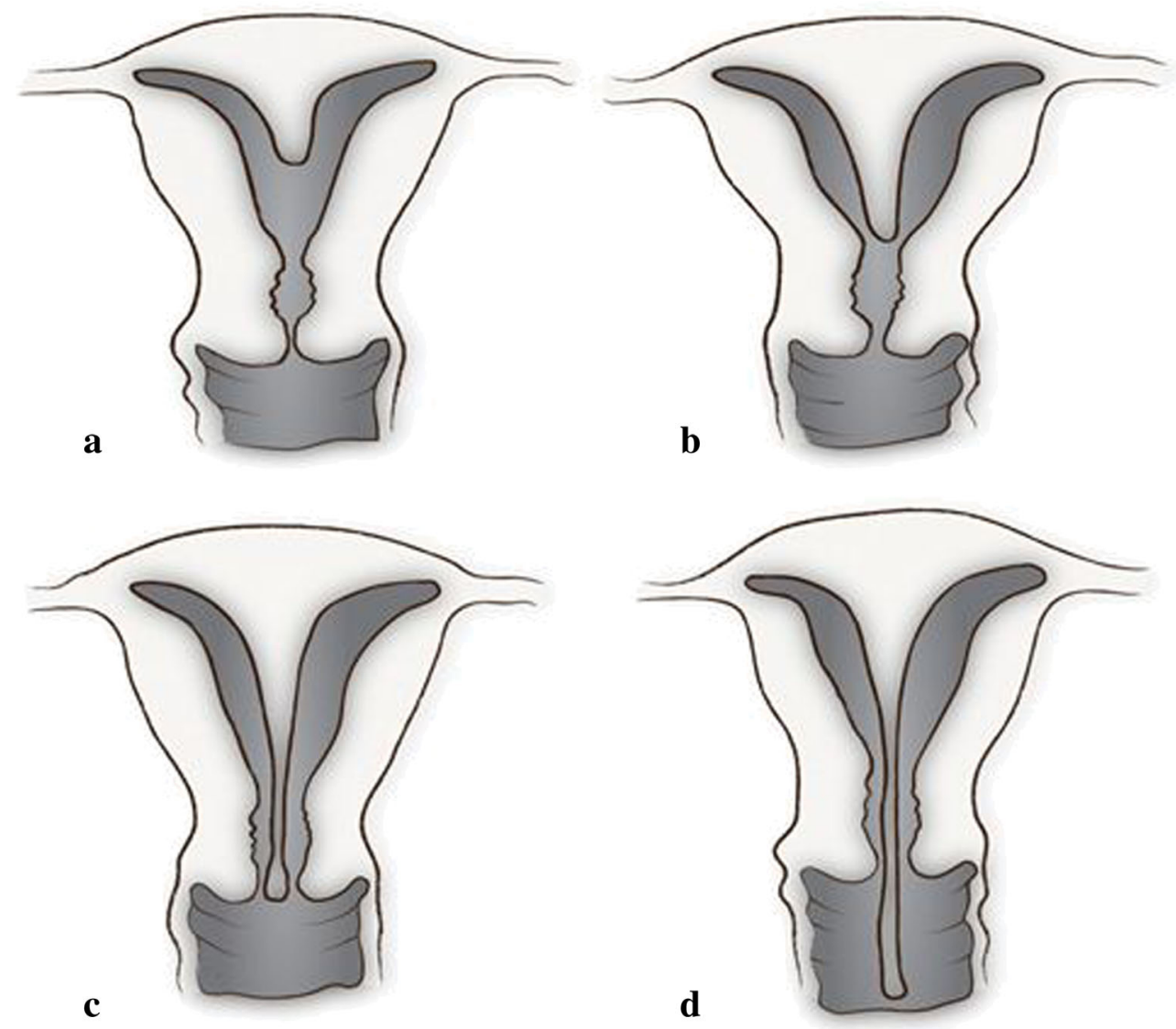

several factors, as diminished blood supply [9], distortion of the uterine cavity, increased intrauterine pressure with resultant cervical incompetence [10], and altered estrogen and progesterone receptor expression [11]. Thus, surgical correction of septate uterus should be considered a first-line treatment whenever indications are present.

Currently, surgical treatment of septate uterus has been significantly simplified by the introduction of hysteroscopic metroplasty, which has almost completely replaced the abdominal approach. Although the reproductive outcome of abdominal and hysteroscopic procedures is similar $[12,13]$, the latter is associated with a reduced complication rate and shorter hospital stay. Therefore, hysteroscopic metroplasty is currently considered the gold standard of these uterine anomalies, as it increases the reproductive outcome with less cost in terms of risk of complications and outflow of resources. Nonetheless, currently available data come mainly from uncontrolled retrospective studies, and to date no randomized trials have been conducted. Considering the resulting lack of evidence, analysis regarding the efficacy of hysteroscopic metroplasty cannot be considered conclusive. Herein, we want to focus on the most relevant literature findings about diagnosis and management of the uterine septum; we also want to analyze the impact of this disease on reproductive outcome.

\section{Methods}

The authors performed a comprehensive search on the PubMed and EMBASE database for published studies with the following keywords: "septate uterus," "hysteroscopic metroplasty," "uterine anomalies," "infertility," and "recurrent miscarriage." We selected studies evaluating diagnosis, impact on fertility, hysteroscopic treatment of septate uterus including original articles, meta-analysis, reviews, and opinion articles published up to August 2013. The authors analyzed embryology, diagnosis, and role of surgical correction on reproductive outcome.

\section{Findings}

Embryology and genetics

In the embryo of 5 to 6 weeks of gestational age, the Müllerian ducts become apparent. They stem from the urogenital ridge as a groove of the coelomic epithelium, growing caudally their medial walls fuse in the midline around 9 weeks and finally join the endodermal evaginations of the urogenital sinus. The process concludes at the end of the first trimester with the 
resorption of the septum, around 19-20 weeks of gestation [14].

Studies conducted on women affected by genetic syndromes, including Müllerian anomalies and knockout mouse models, have allowed the identification of several genes, which play a significant role in the development of the female reproductive system and in the pathogenesis of uterine malformations [15]. An altered expression of the $B c l-2$ gene in uterine septum may prevent apoptosis and uterine septum regression [16]. Mikkilä et al. described an X-linked laterality sequence, in which obligate carrier females had uterine septum and hypertelorism [17]. Ergün et al. reported a rare familial aggregation in three sisters with different degrees of septate uterus [18].

Despite advances in molecular biology and genetics, the precise pathophysiology of septate uterus remains unveiled. The majority of the authors agree that the origin of nearly all uterine malformations is consistent with a polygenic/ multifactorial etiology $[18,19]$.

\section{Diagnosis}

Congenital uterine anomalies are usually asymptomatic and may present with delayed menarche, primary infertility, or recurrent pregnancy loss. Although diagnosis of reproductive malformations can be made during gynecological examination if obvious anomalies of the vagina and cervix are present, the identification of uterine malformations mainly depends on imaging findings. Furthermore, surgical treatment produces clear benefits in terms of reproductive outcome only in the case of a septate uterus; therefore, it is crucial to differentiate this condition from other uterine anomalies $[1-8,20]$. An ideal diagnostic tool should assess two main key points: the shape of the uterine cavity (with the position of tubal ostium) and the external uterine outline. Gubbini et al. proposed a simple, systematic, and reproducible subclassification system for uterine anomalies previously classified by the American Ferility Society as classes V and VI, to achieve a precise definition of each uterine anomaly and determine the specific surgical management [21].

Hysterosalpingography has been the primary diagnostic tool used to detect uterine cavity malformations and is still currently indicated in the early stages of evaluation of the infertile couple. Despite being able to supply important information regarding tubal patency, it does not provide any information on uterine wall or external uterine contour. Moreover, this technique is not reproducible and is not free from risks arising from radiating exposure and/or upper reproductive tract infection [22].

Two-dimensional ultrasound (2D US) mainly performed through an endovaginal approach, offers clear information about the uterine cavity, internal uterine walls, and external uterine outline. Being economic and reproducible, its use is widespread but accuracy chiefly depends on the clinician's experience [23-25]. Sensitivity of 2D US ranges from 88 to $93 \%$ and specificity from 94 to $99 \%$, with a positive predictive value around $50-55 \%$ and a negative predictive value ranging between 88 and $100 \%$ [26-30]. In addition, sonohysterography in which a transonic means expands the uterine cavity enhances ultrasound accuracy in the identification of uterine anomalies providing more detailed information about uterine cavity contour [31-37].

Hysteroscopy offers a direct visual inspection of the cervical canal and uterine cavity. Modern mini-hysteroscopy, combining miniaturization with adequate image quality, has been widely used as a screening tool $[38,39]$. However, it cannot provide any information about uterine wall or external uterine outline. The combined hysteroscopic-laparoscopic approach is considered the best approach in the assessment of women with congenital reproductive malformations, as both internal and external aspect of the uterus can be explored [40]. In addition, coexistent tubal and ovarian anomalies, peritoneal adhesion, or endometriosis can be identified and treated. Nonetheless, like diagnostic tools, this combined approach cannot provide objective measurable data as diagnosis relies on the subjective impression of the examiner. Furthermore, because of the invasive nature, it should not be used as a primary diagnostic tool. The techniques so far described are widely used in the study of Müllerian anomalies, but, if they are considered separately, none is able to provide adequate data on both the uterine cavity and external contour of the uterus. Currently, magnetic resonance imaging (MRI) and three-dimensional ultrasound (3D US) are the only techniques that can assess both aspects contemporarily.

As MRI accuracy in diagnosis of uterine malformations has been demonstrated by several studies [41-44], 3D US represents a good, emerging alternative as it provides image quality similar to that of MRI, being better tolerated by patients and cheaper. A recently introduced MR technique, 3D fastrecovery fast spin-echo (FRFSE) cube can be used to produce high-resolution volumetric image sets. The image data can be reformatted in any plane eliminating the possibility of suboptimal plane prescription using 2D FRFSE technique, regardless of the prescribed plane during the image acquisition (Fig. 2). This is advantageous because variable uterine anatomy in case of Müllerian anomaly may obstacle a correct choice of cross sectional planes in 2D imaging. Furthermore, acquiring just one image volumetric sequence instead of multiple sequences on different planes decreases the MR exam acquisition time with a positive impact on patient comfort [45].

Ghi et al. [46] demonstrated the efficacy of 3D US in differentiating arcuate, subseptate, septate, and bicornuate uterus by analysis of the outer profile of the uterus in coronal plane scans. A bicornuate uterus is diagnosed if a fundal 


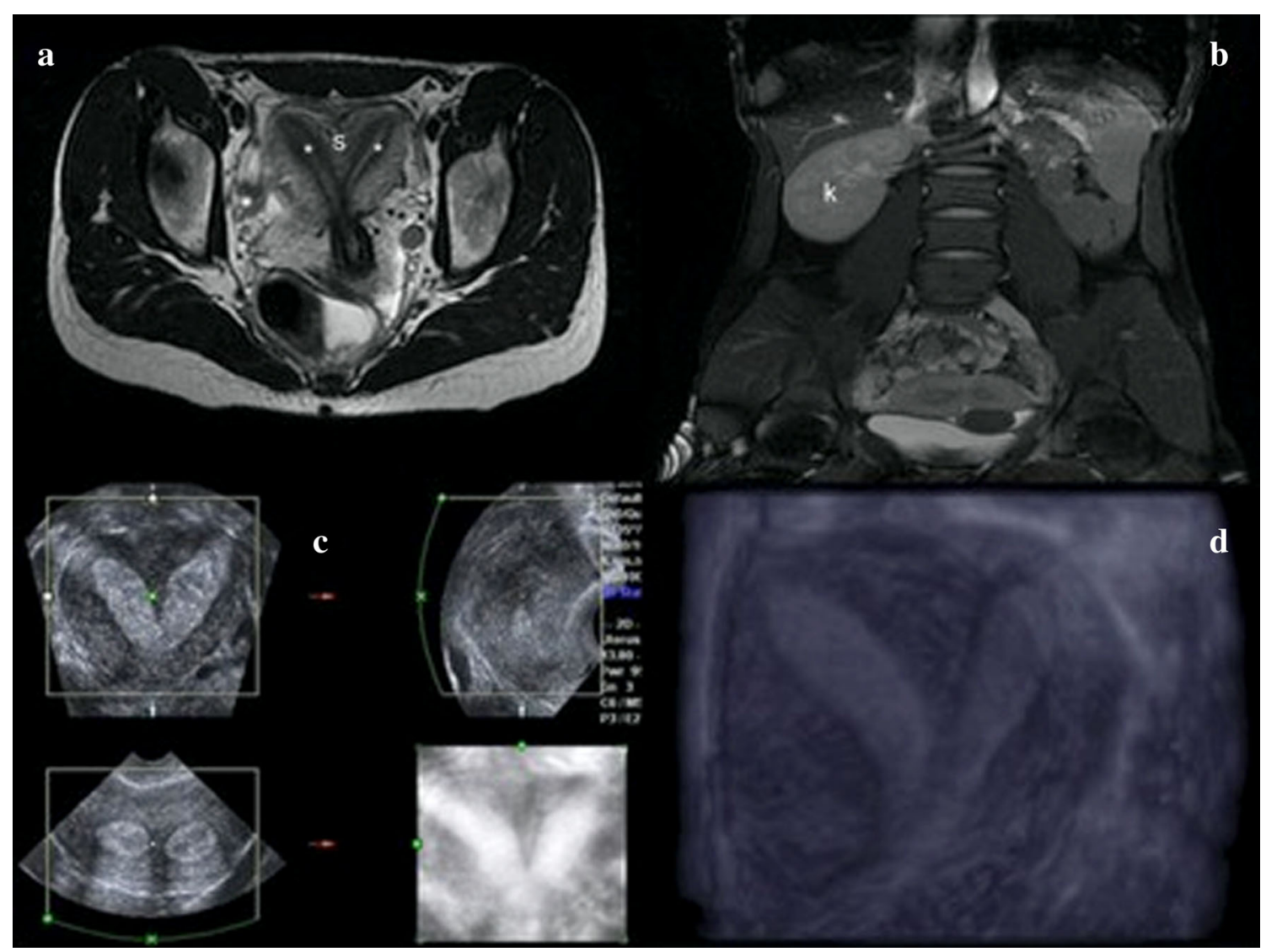

Fig. 2 A case of septate uterus. Axial reformatted 3D FRFSE cube T2 image (a): two distinguished uterine horns (asterisk) with an interposed, complete septum $(s)$ reaching the internal os are depicted. Coronal GE T2

external indentation higher than or equal to $10 \mathrm{~mm}$ divides two separated uterine cornua; conversely, septate, subseptate, and arcuate uteri present a convex fundal outline or a fundal indentation inferior than $10 \mathrm{~mm}$. While in the septate uterus the septum completely divides the cavity from fundus to cervix, in the subseptate and arcuate uteri the septum is bulging inside the uterine cavity drawing an acute or obtuse angle at its central point, respectively.

Bermejo et al. [44] found a high degree of concordance between 3D US and MRI in the diagnosis and classification of uterine malformations [47]. To differentiate bicornuate from septate uteri using 3D US, they used a formula to analyze coronal plane scans, proposed by Troiano and McCarthy [48]: if a line passing through tubal ostia crosses the fundus or its distance from the fundus is less than or equal to $5 \mathrm{~mm}$, it is a bicornuate uterus; if distance is more than $5 \mathrm{~mm}$, it is considered septate uterus, regardless of fundus shape (Fig. 3). Faivre et al. [49] following the diagnostic criteria proposed by the American Fertility Society (AFS) [50] and previously used by Woefler et al. [51] experienced higher diagnostic accuracy of 3D US in detecting septate uterus and differentiating septate from bicornuate uterus, compared with hysteroscopy and MRI. Moreover, the same authors have proposed the use of fat-saturated image (b). Agenesia of the left kidney with hypertrophy of the right kidney $(k)$. 3D ultrasonography image of septate uterus $(\mathbf{c}, \mathbf{d})$

3D sonohysterography when endometrium appears thin or irregular or if other uterine pathologies coexist.

Thus, clinical assessment of women with suspected Müllerian anomalies should be addressed with 3D US, especially before the surgery. With regard to MRI, its high costs

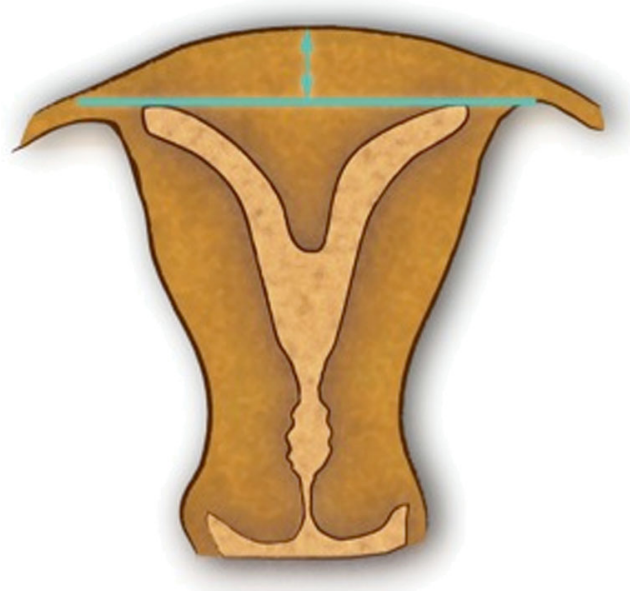

Fig. 3 Septate uterus: the fundus is more than $5 \mathrm{~mm}$ (arrow) above the line passing through tubal ostia 
together with the need of uterine malformation experienced clinicians, limit its use to doubtful or complex cases.

\section{Surgical technique}

Historically, metroplasty for septate uterus has been approached by laparotomic hysterotomy and only in the case of recurrent pregnancy loss. Although both Tompkins and Jones' procedure provided quite good results $[52,53]$, these were highly morbid procedures, resulting in a long time before conception and a subsequent cesarean delivery [54].

In 1974, Edstrom first described the hysteroscopic resection of the uterine septum [55]. Since then, the hysteroscopic surgical technique have been refined and so have been significant diffusion, technical developments have led to miniaturization and improvement of endoscopes resulting in a safer, less-invasive diagnostic and therapeutic tool [56]. Currently, two types of instrument are available for the procedure, namely resectoscope and mini-hysteroscopy, both supporting bipolar and monopolar cautery (Fig. 4). It is best to perform metroplasty in the follicular phase when the endometrium is thin; otherwise, it is possible to administer hormonal therapy as gonadotropin-releasing hormone analog $(\mathrm{GnRH}-\mathrm{a})$ prior to surgery. The surgical technique consists briefly in the incision of the septum, beginning from its inferior apex and proceeding slowly toward the fundus; after, the septum is thinned from both sides under vision while continuously monitoring the position of the ostia, it is then incised in the midsection. As the septum is cut transversely, both edges will retract anteriorly and posteriorly.

The most critical step of this procedure is determining the end point of the resection: if keeping the incision too superficial, it may result in a residual septum and eventually will require an additional operation, whereas, carrying the resection too deep into the fundus, it can lead to intraoperative uterine perforation or uterine rupture during labor or, worse, during subsequent pregnancies.

The procedure usually ends when both ostia are clearly visible from a panoramic view of the uterine cavity and the tip of the instrument can be moved freely from one side to the other, otherwise, when the septum has been adequately resected and minimal bleeding coming from myometrial vessels appears from the bottom of the incision. A few months after surgery, a hysteroscopic evaluation of the uterine cavity may be performed to reveal potential postoperative adhesions

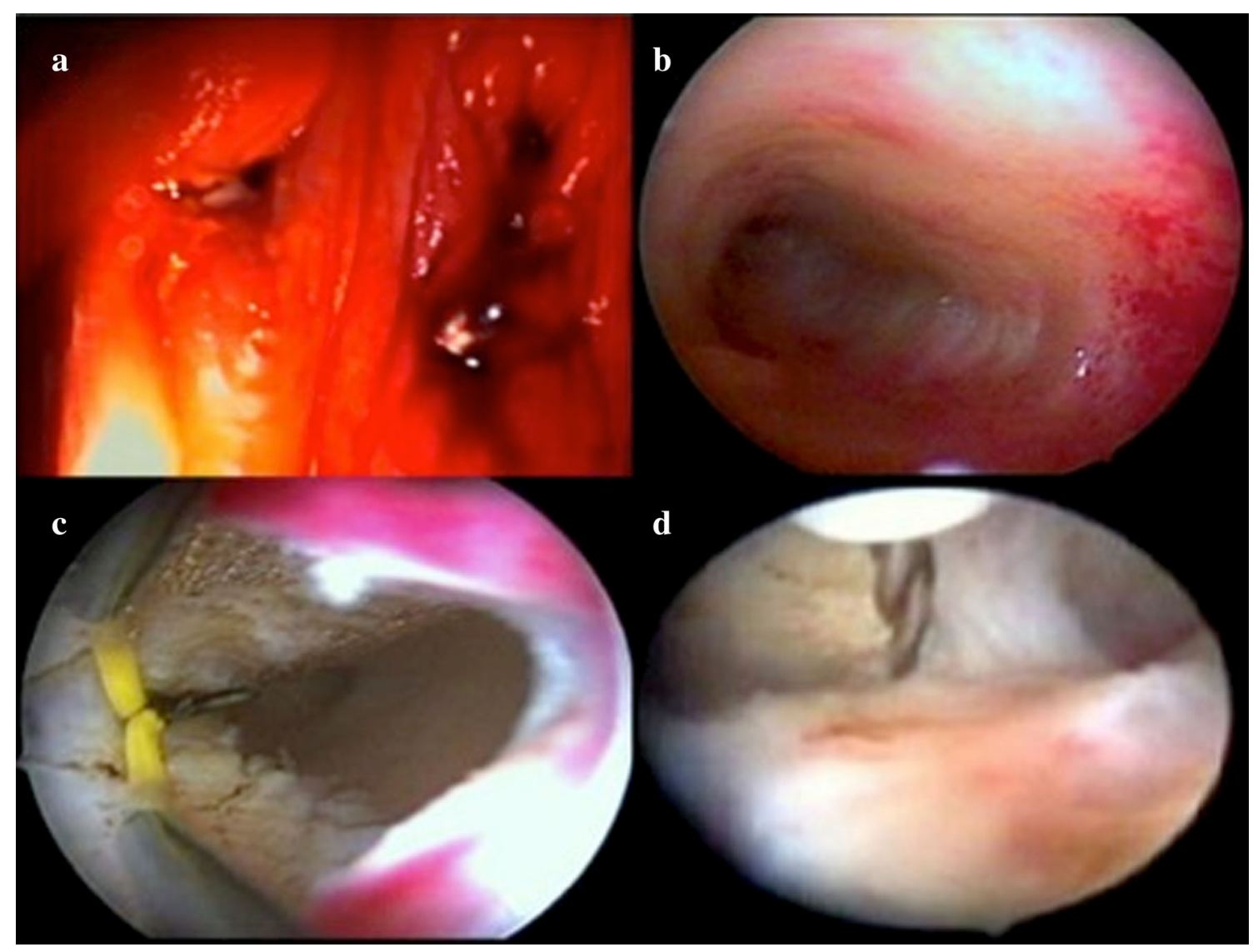

Fig. 4 Septate uterus with double cervix (a, b). Resettoscopic metroplasty with monopolar electrode (c). Small-diameter hysteroscopy with VersaPoint bipolar system $(\mathbf{d})$ 
or a residual septum thicker than $1 \mathrm{~cm}$. The majority of the authors agree that a residual septum inferior to $1 \mathrm{~cm}$ does not worsen the reproductive outcome [57].

The use of laparoscopy, once considered mandatory both during diagnosis (mainly to differentiate the septate from bicornuate uterus) and during surgery (to reveal the relative thickness of the remaining myometrium, through transillumination) has now become quite uncommon. Laparoscopy is occasionally used to conclude a diagnostic work-up in infertile women and is mainly reserved to treat coexisting pathologies.

Traditional resectoscopic techniques make use of 22 or 26 Fr endoscope equipped with a monopolar or bipolar $90^{\circ}$ loop. The procedure is usually performed in the operating theater under general or locoregional anesthesia and is preceded by the dilatation of the cervical canal and distension of the uterine cavity with a non-electrolytic medium if monopolar cautery is used, or with saline solution if bipolar loop is used. It is well known that bipolar energy reduces thermal injury to adjacent tissue compared with monopolar cautery, allowing the use of saline solution as distension media at the same time, which may provide a greater margin in fluid intravasation.

A further advance in the hysteroscopic approach to septate uterus has been achieved in the last decade thanks to the miniaturization of hysteroscopes that allows diagnosis and treatment in the same operative session, with the so-called "see-and-treat" hysteroscopy.

Currently, operative hysteroscopes of small diameter with continuous flow features and operative sheaths are available. Such hysteroscopes allow the use of microscissors or $5 \mathrm{Fr}$ bipolar electrodes. No cervical dilatation is needed, thus reducing cervical trauma, operating time, risk of uterine perforation, and subsequent cervical incompetence, especially in nulliparous infertile women [58]. In addition, numerous studies indicate the possibility to perform the "office" procedure with a short intravenous sedation or no analgesia [53-55]. The efficacy and safety of office hysteroscopy with a VersaPoint device were assessed by two major studies that compared this technique with traditional monopolar [54-57]. Although reproductive outcomes (pregnancy rate, live births rate, and miscarriages rate) were similar in both techniques, hysteroscopy performed with VersaPoint was found to be safer and easier (as no dilatation was needed). Furthermore, it granted better haemostasis and could be used both in nulligravide and in women with stenosis of the cervical canal. Colacurci et al. [54] in a randomized, multicentre trial found no difference in reproductive outcomes between women treated by a bipolar microelectrode and those treated by resectoscope with monopolar knife, whereas operative time, fluid absorption, and complication rates were higher with resectoscopy.

Although, "office" hysteroscopic metroplasty with bipolar electrodes is fully equivalent to monopolar resectoscope in terms of reproductive outcome, the choice of either depends on the costs of the instrumentation, the availability of the operating room, operative time and complication rate.

The advantages of classic resectoscopy include availability and low cost instruments. Conversely, considering the advantages in terms of operative time, increased safety and higher feasibility, mini-hysteroscopy is a viable alternative to traditional resectoscopy and therefore should be preferred in case of subseptate uterus (class $\mathrm{Vb}$ ).

Only in the case of septate uterus (septum extends up to the cervix) should the use of the classic resectoscope be preferred, as a continuous loss of distension medium through a widely patent cervical canal may occur; this can lead to insufficient expansion of the uterine cavity and hence a suboptimal view of the surgical field.

\section{Septate uterus and reproductive outcome}

Obstetric complications Approximately 20-25\% women with septate uterus experience obstetric complications and, among these, recurrent miscarriage and preterm labor are the most common [59].

A retrospective review conducted in 2001 on 198 women with septate uterus and a total of 499 pregnancies, indicated a prevalence of $44.1 \%$ of miscarriage, $22.3 \%$ of preterm labor, and $32.9 \%$ for term delivery [60]. Similar results have been reported by other authors during the last years, confirming poor pregnancy outcome related to the presence of uterine septum. Therefore, reproductive outcome in women with septate uterus is the reference parameter used to assess the efficacy of hysteroscopic metroplasty. Numerous studies have already demonstrated a significant decrease of abortion and preterm labor rate in women treated with hysteroscopic metroplasty [61-69]. In a series of 366 pregnancies following hysteroscopic septum resection, just 60 cases of recurrent abortion (16.4\%) and 25 cases of preterm labor (6.8\%) were observed. These results were significantly improved when compared with preoperative rates, $86.4 \%$ for miscarriage and $9.8 \%$ for preterm labor [60].

The prophylactic role of metroplasty in asymptomatic or nulliparous women is still debated. The increased risk of uterine rupture in subsequent pregnancies and the need for a cesarean section would limit the surgical removal of the septum only to symptomatic women [59, 70]. Conversely, scientific evidence indicates a clear association between septate uterus and poor pregnancy outcome and a significant improvement of the reproductive outcome after resection. Considering the safety and feasibility of hysteroscopic metroplasty in the hands of an experienced surgeon, several authors have taken into account the possibility of using it as a prophylactic tool [71]. 
Infertility During the last two decades, contradictory results about the role of uterine malformations in fertility have been reported [23, 60, 72, 73]. Although uterine malformations may interfere with embryonic implantation and placentation [67], a review by Grimbizis et al. [60] found a similar prevalence of uterine malformations in infertile women and in the general population. These findings were confirmed by other authors $[20,66]$. Thus, a direct correlation between uterine malformations and infertility should be excluded. Conversely, arcuate uterus is the most common uterine malformation in the fertile population and, in addition, the prevalence of septate uterus among infertile women is twice as high as that observed in the general population. These data support a relation between septate uterus and female infertility [74], especially in secondary infertility [66].

The discrepancy of data available in literature is reflected in clinical practice when metroplasty is used in cases of unexplained female infertility, to improve pregnancy rates. Still, data available are not conclusive, coming mostly from retrospective studies, conducted over small numbers of patients, often selected by different criteria.

A systematic review conducted by Homer et al. found a pregnancy rate of $48 \%$ after resection in women with primary sterility and thereby supporting the use of hysteroscopic metroplasty in these cases [69]. The first prospective study on the use of metroplasty in infertile women was published in 2004 by Pabuccu et al. [73], reporting a postoperative spontaneous pregnancy rate of $41 \%$ in women with infertility of unknown cause. These results were confirmed by prospective controlled trial by Mollo et al. on 44 women affected by septate uterus and otherwise unexplained infertility and 132 women with unexplained infertility as control [71]; the authors found a significantly higher pregnancy rate (38.6 vs $20.4 \%$ ) and live birth rate (34.1 vs $18.9 \%)$ in the metroplasty group than in the control group. Similar outcome is achieved from a study by Shokeir et al. in 2011 [34], highlighting a postoperative pregnancy rate of $40.7 \%$ with $80 \%$ spontaneous conceptions. Although there are no randomized controlled trials, published data from 1986 to 2011 of hysteroscopic metroplasty in patients with primary infertility showed a pregnancy rate of about $40 \%$ (16-74\%) (Table 1).

With regard to the need for metroplasty prior to a program for assisted reproduction (hence consisting of an infertile female population), most authors agree with the benefits of hysteroscopic resection of endometrial polyps, submucous fibroids, and uterine septum in terms of reproductive outcome. Tomazevic et al. studied approximately 2,500 patients affected by septate uterus (complete, subseptate uterus, and arcuate uterus) and undergoing an assisted reproduction program. They found that hysteroscopic metroplasty prior to in vitro
Table 1 Pregnancy rate after hysteroscopic metroplasty for the septate uterus in women with primary infertility

\begin{tabular}{llll}
\hline Author & $\begin{array}{l}\text { No. of patients who } \\
\text { underwent hysteroscopic } \\
\text { metroplasty for } \\
\text { septate uterus }\end{array}$ & $\begin{array}{l}\text { No. of patients } \\
\text { with primary } \\
\text { infertility }\end{array}$ & $\begin{array}{l}\text { Pregnancy } \\
\text { rate (\%) }\end{array}$ \\
\hline Fayez [11] & 19 & 7 & 36 \\
Perino [54] & 24 & 8 & 33 \\
Daly [55] & 70 & 15 & 21 \\
Marabini [74] & 40 & 14 & 35 \\
Pabuccu [75] & 59 & 10 & 16 \\
Colacurci [76] & 69 & 21 & 30 \\
Venturoli [77] & 69 & 36 & 52 \\
Pabuccu [71] & 61 & 25 & 40 \\
Colacurci [52] & 35 & 26 & 74 \\
Mollo[69] & 44 & 17 & 38 \\
Wang [78] & 6 & 2 & 33 \\
Pai [79] & 64 & 33 & 51 \\
Tongue [80] & 102 & 44 & 43 \\
Total & 662 & 258 & 39 \\
\hline
\end{tabular}

fertilization (IVF) or intracytoplasmic sperm injection, significantly increased pregnancy rates and live birth rates [75]. Therefore, in accordance with Homer [69], they conclude that hysteroscopic correction of uterine abnormalities is a feasible, safe technique that improves reproductive outcome not only in women with recurrent pregnancy loss and preterm labor but also in infertile women, especially if IVF is being contemplated.

\section{Conclusions}

Septate uterus results from the incomplete or completely failed fusion of Müllerian ducts. Approximately 20$25 \%$ of women with septate uterus experience obstetric complications that required a hysteroscopic surgery. Although obstetric complications represent the main indications for metroplasty, a possible negative role of uterine septum in case of otherwise unexplained infertility cannot be excluded. The scientific evidence does not show a direct etiological nexus but are not conclusive and require further study. According to the latest data, considering the simplicity and safety of hysteroscopic metroplasty, it seems safe to indicate the use in infertile women, especially if nulliparous over 35 years of age [23] or who intend to undergo a program of PMA [59].

Conflict of interest The authors declare no conflict of interest. 


\section{References}

1. Raga F, Bauset C, Remohi J, Bonilla-Musoles F, Simon C, Pellicer A (1997) Reproductive impact of congenital Mullerian anomalies. Hum Reprod 12:2277-2281

2. Taylor E, Gomel V (2008) The uterus and fertility. Fertil Steril 89:116

3. Giraldo JL, Habana A, Duleba AJ, Dokras A (2000) Septate uterus associated with cervical duplication and vaginal septum. J Am Assoc Gynecol Laparosc 7(2):277-279

4. Hundley AF, Fielding JR, Hoyte L (2001) Double cervix and vagina with septate uterus: an uncommon müllerian malformation. Obstet Gynecol 98(5 Pt 2):982-985

5. Wai CY, Zekam N, Sanz LE (2001) Septate uterus with double cervix and longitudinal vaginal septum. A case report. J Reprod Med 46(6): 613-617

6. Saygili-Yilmaz ES, Erman-Akar M, Bayar D, Yuksel B, Yilmaz Z (2004) Septate uterus with a double cervix and longitudinal vaginal septum. J Reprod Med 49(10):833-836

7. Grimbizis GF, Gordts S, Di Spiezio Sardo A, Brucker S, De Angelis $\mathrm{C}$, Gergolet $\mathrm{M}$ et al (2013) The ESHRE-ESGE consensus on the classification of female genital tract congenital anomalies. Gynecol Surg 10(3):199-212

8. Chan YY, Jayaprakasan K, Zamora J, Thornton JG, Raine-Fenning $\mathrm{N}$, Coomarasamy A (2011) The prevalence of congenital uterine anomalies in unselected and high-risk populations: a systematic review. Hum Reprod Update 17(6):761-771

9. Burchell RC, Creed F, Rasoulpour M, Whitcomb M (1978) Vascular anatomy of the human uterus and pregnancy wastage. Br J Obstet Gynaecol 85:698-706

10. Candiani GB, Fedele L, Zamberletti D, De Virgiliis D, Carinelli S (1983) Endometrial patterns in malformed uteri. Acta Eur Fertil 14: 35-42

11. Rock JA, Murphy AA (1986) Anatomic abnormalities. Clin Obstet Gynecol 29:886-911

12. Fayez JA (1986) Comparison between abdominal and hysteroscopic metroplasty. Obstet Gynecol 68:399-403

13. Heinonen PK (1997) Reproductive performance of women with uterine anomalies after abdominal or hysteroscopic metroplasty or no surgical treatment. J Am Assoc Gynecol Laparosc 4:311-317

14. Valle RF, Ekpo GE (2013) Hysteroscopic metroplasty for the septate uterus: review and metanalysis. J Minim Invasive Gynecol 20(1):22-42

15. Connell MT, Owen CM, Segars JH (2013) Genetic syndromes and genes involved in the development of the female reproductive tract: a possible role for gene therapy. J Genet Syndr Gene Ther 4:2

16. Lee DM, Osathanondh R, Yeh J (1998) Localization of Bcl-2 in the human fetal müllerian tract. Fertil Steril 70:135-140

17. Mikkila SP, Janas M, Karikoski R, Tarkkila T, Simola KO (1994) Xlinked laterality sequence in a family with carrier manifestations. Am J Med Genet 49:435-438

18. Ergun A, Pabuccu R, Atay V, Kucuk T, Duru NK, Gungor S (1997) Three sisters with septate uteri: another reference to bidirectional theory. Hum Reprod 12:140-142, 9

19. Wu MH, Hsu CC et al (1997) Detection of congenital Mullerian duct anomalies using three-dimensional ultrasound. J Clin Ultrasound 25(9):487-492

20. Saravelos SH, Cocksedge KA, Li TC (2008) Prevalence and diagnosis of congenital uterine anomalies in women with reproductive failure: a critical appraisal. Hum Reprod Update 14(5):415-429

21. Gubbini G, Di Spiezio Sardo A, Nascetti D, Marra E, Spinelli M, Greco E, Casadio P, Nappi C (2009) New outpatient subclassification system for American Fertility Society classes V and VI uterine anomalies. J Minim Invasive Gynecol 16(5):554-561

22. Reuter K, Daly DC, Cohen SM (1989) Septate versus bicornuate uteri: errors in imaging diagnosis. Radiology 172:749-752

23. Kupesic S (2001) Clinical implications of sonographic detection of uterine anomalies for reproductive outcome. Ultrasound Obstet Gynecol 18:387-400

24. Mazouni C, Girard G, Deter R, Haumonte J-B, Blanc B, Bretelle F (2008) Diagnosis of Mullerian anomalies in adults: evaluation of practice. Fertil Steril 89:219-222

25. Ludwin A, Pityński K, Ludwin I, Banas T, Knafel A (2013) Two- and three-dimensional ultrasonography and sonohysterography versus hysteroscopy with laparoscopy in the differential diagnosis of septate, bicornuate, and arcuate uteri. J Minim Invasive Gynecol 20(1):90-99

26. Nicolini U, Bellotti M, Bonazzi B, Zamberletti D, Candiani GB (1987) Can ultrasound be used to screen uterine malformations? Fertil Steril 47:89-93

27. Fedele L, Ferrazzi E, Dorta M, Vercellini P, Candiani GB (1988) Ultrasonography in the differential diagnosis of "double" uteri. Fertil Steril 50:361-364

28. Salle B, Sergeant P, Gaucherand P, Guimont I, de Saint Hillaire P, Rudigoz RC (1996) Transvaginal hysterosonographic evaluation of septate uteri: a preliminary report. Hum Reprod 11:1004-1007

29. Storment JM, Kaiser JR, Sites CK (1998) Transvaginal ultrasonographic diagnosis of uterine septa. J Reprod Med 43:823-826

30. Perino A, Catinella E, Comparetto G, Venezia R, Candela P, Cimino C, Zangara C, Mencaglia L (1987) Hysteroscopic metroplasty: the role of ultrasound in the diagnosis and monitoring of patients with uterine septa. Acta Eur Fertil 18(5):349-352

31. Grimbizis GF, Tsolakidis D, Mikos T, Anagnostou E, Asimakopoulos E, Stamatopoulos P, Tarlatzis BC (2010) A prospective comparison of transvaginal ultrasound, saline infusion sonohysterography, and diagnostic hysteroscopy in the evaluation of endometrial pathology. Fertil Steril 94:2720-2795

32. Guimarães Filho HA, Mattar R, Pires CR, Araujo Junior E, Moron AF, Nardozza LMM (2006) Comparison of hysterosalpingography, hysterosonography and hysteroscopy in evaluation of the uterine cavity in patients with recurrent pregnancy losses. Arch Gynecol Obstet 274:284-288

33. Guven MA, Bese T, Demirkiran F, Idil M, Mgoyi L (2004) Hydrosonography in screening for intracavitary pathology in infertile women. Int J Gynecol Obstet 86:377-383

34. Shokeir T, Abdelshaheed M, El-Shafie M, Sherif L, Badawy A (2011) Determinants of fertility and reproductive success after hysteroscopic septoplasty for women with unexplained primary infertility: a prospective analysis of 88 cases. Eur J Obstet Gynecol Reprod Biol 155(1):54-57

35. Shokeir S, Abdelshaheed M (2009) Sonohysterography as a first-line evaluation for uterine abnormalities in women with recurrent failed in vitro fertilization-embryo transfer. Fertil Steril 91(suppl 4):1321-1322

36. Tur-Kaspa I, Gal M, Hartman M, Hartman J, Hartman A (2006) A prospective evaluation of uterine abnormalities by saline infusion sonohysterography in 1009 women with infertility or abnormal uterine bleeding. Fertil Steril 86:1731-1735

37. Valenzano MM, Mistrangelo E, Lijoi D, Fortunato T, Lantieri PB, Risso D, Costantini S, Ragni N (2006) Transvaginal sonohysterographic evaluation of uterine malformations. Eur J Obstet Gynecol Reprod Biol 124:246-249

38. Campo R, Van Belle Y, Rombauts L, Brosens I, Gordts S (1999) Office mini-hysteroscopy. Hum Reprod Update 5:73-81

39. Gordts S, Campo R, Puttemans P, Verhoven H, Gianaroli L, Brosens J, Brosens I (2002) Investigation of the infertile 
couple: a one stop outpatient endoscopy-based approach. Hum Reprod 17:1684-1687

40. Philbois O, Guye E, Richard O, Tardieu D, Seffert P, Chavrier Y, Varlet F (2004) Role of laparoscopy in vaginal malformation. An experience in 22 children. Surg Endosc 18:87-91

41. Fedele L, Dorta M, Brioschi D, Massari C, Candiani GB (1989) Magnetic resonance evaluation of double uteri. Obstet Gynecol 74:844 847,11

42. Carrington BM, Hricak H, Nuruddin RN, Secaf E, Laros RK Jr, Hill EC (1990) Mullerian duct anomalies: MR imaging evaluation. Radiology 176:715-720

43. Pellerito JS, McCarthy SM, Doyle MB, Glickman MG, DeCherney AH (1992) Diagnosis of uterine anomalies: relative accuracy of MR imaging, endovaginal sonography and hysterosalpingography. Radiology 183:795-800

44. Fischetti SG, Politi G, Lomeo E, Garozzo G (1995) Magnetic resonance in the evaluation of Mullerian duct anomalies. Radiol Med 89: 105-111

45. Agrawal G, Riherd JM, Busse RF, Hinshaw JL, Sadowski EA (2009) Evaluation of uterine anomalies: 3D FRFSE cube versus standard 2D FRFSE. AJR 193:558-562

46. Ghi T, Casadio P, Kuleva M, Perrone AM, Savelli L, Giunchi S et al (2009) Accuracy of three-dimensional ultrasound in diagnosis and classification of congenital uterine anomalies. Fertil Steril 92(2):808 813

47. Bermejo C, Ten Martínez P, Cantarero R, Diaz D, Pérez Pedregosa J, Barrón E, Labrador E et al (2010) Three-dimensional ultrasound in the diagnosis of Müllerian duct anomalies and concordance with magnetic resonance imaging. Ultrasound Obstet Gynecol 35:593-601

48. Troiano R, Mc Carthy S (2004) Mülleriane duct anomalies: imaging and clinical issues. Radiology 233:19-34

49. Faivre E, Fernandez H, Deffieux X, Gervaise A, Frydman R, Levaillant JM (2012) Accuracy of three-dimensional ultrasonography in differential diagnosis of septate and bicornuate uterus compared with office hysteroscopy and pelvic magnetic resonance imaging. J Minim Invasive Gynecol 19(1):101-106

50. The American Fertility Society (1988) The American Fertility Society classi- fication of adnexal adhesions, distal tubal occlusion, tubal occlusion secondary to tubal ligation, tubal pregnancies, Mullerian anomalies and intrauterine adhesions. Fertil Steril 49: 944-955

51. Woelfer B, Salim R, Banerjee S, Elson J, Regan L, Jurkovic D (2001) Reproductive outcomes in women with congenital anomalies detected by three-dimensional ultrasound screening. Obstet Gynecol 98: 1099-1103

52. Manuale per un'isteroscopia moderna. Gruppo Isteroscopisti della Scuola Italiana di Chirurgia Mini Invasiva Ginecologica. Cap 19.

53. Bettocchi S, Ceci O, Nappi L, Pontrelli G, Pinto L, Vicino M (2007) Office hysteroscopic metroplasty: three "diagnostic criteria" to differentiate between septate and bicornuate uteri. J Minim Invasive Gynecol 14(3):324-328

54. Colacurci N, De Franciscis P, Mollo A, Litta P, Perino A, Cobellis L, De Placido G (2007) Small-diameter hysteroscopy with VersaPoint versus resectoscopy with a unipolar knife for the treatment of septate uterus: a prospective randomized study. J Minim Invasive Gynecol 14(5):622-627

55. Edstrom K (1974) Intrauterine surgical procedures during hysteroscopy. Endoscopy 6:175-181

56. Perino A, Castelli A, Cucinella G, Biondo A, Pane A, Venezia R (2004) A randomized comparison of endometrial laser intrauterine thermotherapy and hysteroscopic endometrial resection. Fertil Steril 82(3):731-734
57. Litta P, Spiller E, Saccardi C, Ambrosini G, Caserta D, Cosmi E (2008) Resectoscope or VersaPoint for hysteroscopic metroplasty. Int J Gynaecol Obstet 101(1):39-42

58. Lavergne N, Aristizabal J, Zarka V, Erny R, Hedon B (1996) Uterine anomalies and in vitro fertilization: what are the results? Eur J Obstet Gynecol Reprod Biol 68:29-34

59. Lourdel E, Cabry-Goubet R, Merviel P, Grenier N, Oliéric M-F, Gondry J (2007) Septate uterus: role of hysteroscopic metroplasty. Gynécol ObstétFertil 35:811-818

60. Grimbizis GF, Camus M, Tarlatzis BC, Bontis JN, Devroey P (2001) Clinical implications of uterine malformations and hysteroscopic treatment results. Hum Reprod Update 7(1):161-174

61. De Cherney HA, Russell BJ, Graebe AR, Polan M-L (1986) Resectoscopic management of Mullerian fusion defects. Fertil Steril 45:726-729

62. Valle FR, Sciarra JJ (1986) Hysteroscopic treatment of the septate uterus. Obstet Gynecol 67:253-257

63. March MC, Israel R (1987) Hysteroscopic management of recurrent abortion caused by septate uterus. Am J Obstet Gynecol 156:834 842

64. Perino A, Mencaglia L, Hamou J, Cittadini E (1987) Hysteroscopy for metroplasty of uterine septa: report of 24 cases. Fertil Steril 48: 321-323

65. Daly CD, Maier D, Soto-Albors C (1989) Hysteroscopic metroplasty: six years experience. Obstet Gynecol 73:201-205

66. Choe KJ, Baggish SM (1992) Hysteroscopic treatment of septate uterus with neodymium-YAG laser. Fertil Steril 57:81-84

67. Fedele L, Arcaini L, Parazzini F et al (1993) Reproductive prognosis after hysteroscopic metroplasty in 102 women: life-table analysis. Fertil Steril 59:768-772

68. Grimbizis G, Camus M, Clasen K et al (1998) Hysteroscopic septum resection in patients with recurrent abortions and infertility. Hum Reprod 13:1188-1193

69. Horner HA, Li T-C, Cooke ID (2000) The septate uterus: a review of management and reproductive outcome. Fertil Steril 73:1-14

70. Patton PE, Novy MJ, Lee DM, Hickok LR (2004) The diagnosis and reproductive outcome after surgical treatment of the complete septate uterus, duplicated cervix and vaginal septum. Am J Obstet Gynecol 190(6):1669-1675

71. Mollo A, De Franciscis P, Colacurci N, Cobellis L, Perino A, Venezia R, Alviggi C, De Placido G (2009) Hysteroscopic resection of the septum improves the pregnancy rate of women with unexplained infertility: a prospective controlled trial. Fertil Steril 91(6):26282631

72. Heinonen PK, Pystynen PP (1983) Primary infertility and uterine anomalies. Fertil Steril 40:311-316

73. Pabuccu R, Gomel V (2004) Reproductive outcome after hysteroscopic metroplasty in women with septate uterus and otherwise unexplained infertility. Fertil Steril 81:1675-1678

74. Nahum GG (1998) Uterine anomalies. How common are they, and what is their distribution among subtypes? J Reprod Med 43:877887

75. Tomazevic T, Ban-Frangez H, Virant-Klun I, Verdenik I, Pozlep B, Vrtacnik-Bokal E (2010) Septate, subseptate and arcuate uterus decrease pregnancy and live birth rates in IVF/ICSI. Reprod Biomed Online 21:700-705

76. Marabini A, Gubbini G, Stagnozzi R, Stefanetti M, Filoni M, Bovicelli A (1994) Hysteroscopic metroplasty. Ann N Y Acad Sci 734:488-492

77. Pabuccu R, Atay V, Urman B, Ergun A, Orhon E (1995) Hysteroscopic treatment of septate uterus. Gynaecol Endosc 4:213-215 
78. Colacurci N, De Placido G, Mollo A, Carravetta C, De Francisicis P (1996) Reproductive outcome after hysteroscopic metroplasty. Eur J Obstet Gynecol Reprod Biol 66:147-150

79. Venturoli S, Colombo FM, Vianello F, Seracchioli R, Possati G, Parasidi R (2002) A study of hysteroscopic metroplasty in 141 women with a septate uterus. Arch Gynecol Obstet 266:157-159

80. Wang JH, Xu K-H, Lin J, Chen XZ (2009) Hysteroscopic septum resection of complete septate uterus with cervical duplication, sparing the double cervix in patients with recurrent spontaneous abortions or infertility. Fertil Steril 91:2643-2649

This article does not contain any studies with human or animal subjects performed by the any of the authors. 